\title{
An audit of surgical site infection following open prostatectomy in a Nigerian Teaching Hospital
}

\author{
Abdulkadir A Salako ${ }^{1,2}$, Tajudeen A Badmus ${ }^{1,2}$, Chiazor U Onyia ${ }^{2}$, Rotimi A David ${ }^{2}$, \\ Ifedayo E Adejare ${ }^{3}$, Adekunle O Lawal ${ }^{3}$, Chigozie I Onyeze ${ }^{2}$, Chinedu U Ndegbu ${ }^{2}$
}

1. Department of Surgery, Obafemi Awolowo University, Ile-Ife, Nigeria.

2. Department of Surgery, Obafemi Awolowo University Teaching Hospitals Complex, Ile-Ife, Nigeria.

3. Department of Surgery, Federal Medical Centre, Owo, Nigeria.

\begin{abstract}
Background: Surgical site infections (SSI) are a potential cause of morbidity and increased cost of care after operations such as open prostatectomy.

Objective: To audit the occurrence of SSI after open prostatectomy at the Obafemi Awolowo University Teaching Hospitals Complex (OAUTHC), Ile-Ife, Nigeria

Methods: A review of all patients who underwent open prostatectomy over a ten-year period (July 2005 to June 2015). Data analysis was done using the statistical package for social sciences version 21. Association between variables was determined using Chi-square or Fisher's exact test as appropriate. A p-value $<0.05$ was considered statistically significant.

Results: A total of 247 open prostatectomy surgeries were reviewed, with the patients' ages ranging from 43 - 91 years and a mean age of $67.0 \pm 8.8$ years. Elective procedures were $98.8 \%$ while the remaining $1.2 \%$ were emergency cases. There were $24(9.8 \%)$ surgical site infections. The duration of admission of the patients with SSI ranged from $6-15$ days with a mean of $9.5 \pm 3.2$ days, as against $4-9$ days (mean of $5.0 \pm 2.1$ days) for those without SSI. All the patients with SSI were successfully managed with no resultant mortality. Risk factors identified for SSI were emergency surgery $(p=0.001)$, obesity $(p<0.0001)$, diabetes mellitus $(p=0.008)$, smoking $(p<0.0001)$, pre-operative catheterization $(p<0.0001)$, excessive haemorrhage $(p<0.0001)$ and post-operative suprapubic bladder drainage $(\mathrm{p}<0.0001)$.

Conclusion: SSI is a recognized complication of open prostatectomy. Identified risk factors for its occurrence from this audit are emergency operation, obesity, diabetes mellitus, smoking, pre-operative catheterization, excessive haemorrhage and post-operative suprapubic bladder drainage. Age, approach to prostatectomy (retropubic vs transvesical), incision type (lower midline vs pfannenstiel), level of the surgeon, catheter type and modality of irrigation were however not significant risk factors for post-prostatectomy SSI in this study.
\end{abstract}

Keywords: Surgical site infection, risk factors, open prostatectomy.

DOI: https://dx.doi.org/10.4314/ahs.v19i2.30

Cite as: Salako AA, Badmus TA, Onyia CU, David RA, Adejare IE, Lawal AO, Onyeze CI, Ndegbu CU. An audit of surgical site infection following open prostatectomy in a Nigerian Teaching Hospital. Afri Health Sci.2019;19(2): 2068-2072. https://dx.doi.org/10.4314/ahs. v19i2.30

\section{Introduction}

Surgical site infections (SSI) can occur within 30-days after surgery (up to one year after implant surgery) and affect either the incision bed or deep tissues at the operation site $^{1}$. They are adverse surgical sequel which could lead to significant morbidity, patient discomfort and increased cost of surgical care, since they impose severe demands

\section{Corresponding author:}

Chiazor U Onyia,

Department of Surgery,

Obafemi Awolowo University

Teaching Hospitals Complex, Ile-Ife, Nigeria.

Email: shalomazor@yahoo.com on the already meager health care resources ${ }^{2,3}$. Although transurethral resection of the prostate has become the gold-standard, open simple prostatectomy is however still carried out for treatment of patients with benign prostate hyperplasia (BPH) in our environment because of the relatively large prostate size encountered possibly due to genetic predisposition and/or late patient presentation ${ }^{4,5}$. In addition, open prostatectomy has the lowest failure rate among the different surgical options for BPH and can be used to simultaneously tackle complications such as bladder diverticulum during same surgery ${ }^{6}$. However, as with any other surgical procedure, it can be followed by infective complications and this review is an outcome audit of SSI in patients who had open simple prostatectomy at our university teaching hospital in SouthWestern Nigeria over 
a 10 -year period. The aim was to determine the incidence of post-prostatectomy SSI and identify possible risk factors for its occurrence.

\section{Methods}

The study was conducted at the Obafemi Awolowo University Teaching Hospitals Complex (OAUTHC), Ile-Ife; a 733-bedded tertiary hospital located in SouthWestern Nigeria. The record of all patients who had open simple prostatectomy in the hospital between July 2005 and June 2015 were reviewed after obtaining ethical approval. Key criteria for inclusion were either transvesical or retropubic prostatectomy within the specified period. The patients were evaluated in our out-patient clinic 2-6 weeks before surgery. Their urine dipstick was repeated on admission and those suggestive of urinary tract infection (UTI) in this immediate pre-operative period were excluded. All the patients recruited had antibiotic prophylaxis at induction of anaesthesia based on local microbiological guidelines. Those that developed post-prostatectomy SSI were identified based on a combination of clinical and microbiological evaluation and their demographic characteristics, clinical presentation, SSI risk factors, duration of admission and treatment outcome were extracted and analyzed using the statistical package for social sciences (SPSS) version 21. Cross tabulation was done and association between variables was determined using Chi-square or Fisher's exact test as appropriate. A p-value $<0.05$ was considered statistically significant.

\section{Results}

A total of 247 open simple prostatectomy operations were performed during the period under review, with age range of the patients being 43 - 91 years (mean age 67.0 \pm 8.8 years). The operations were elective procedures in 244 patients $(98.8 \%)$ and emergency in 3 patients $(1.2 \%)$. There were $24(9.8 \%)$ cases of SSI and their identified risk factors are elucidated in Table 1. The duration of admission in the patients with SSI ranged from 6-15days (mean of $9.5 \pm 3.2$ days), as against 4-9 days (mean of 5 \pm 2.1 days) in those without SSI. All the patients with SSI were successfully treated using conservative measures.

Table 1: Risk factors for surgical site infection

\begin{tabular}{|c|c|c|c|c|}
\hline Parameter & & Total number (\%) & Number with SSI (\%) & Statistical analyses \\
\hline \multirow{5}{*}{ Age } & $40-50$ years & $7(2.8)$ & $1(4.2)$ & \multirow{5}{*}{$\mathrm{FET}=0.946 ; \mathrm{p}=0.942$} \\
\hline & $51-60$ years & $62(25.1)$ & $5(20.8)$ & \\
\hline & $61-70$ years & $97(39.3)$ & $10(41.7)$ & \\
\hline & $71-80$ years & $69(27.9)$ & $7(29.1)$ & \\
\hline & $>80$ years & $12(4.9)$ & $1(4.2)$ & \\
\hline \multirow[t]{2}{*}{ Timing of surgery } & Elective & $244(98.8)$ & $21(87.5)$ & \multirow[t]{2}{*}{$\mathrm{FET}=28.22 ; \mathrm{df}=1 ; \mathrm{p}=0.001$} \\
\hline & Emergency & $3(1.2)$ & $3(12.5)$ & \\
\hline \multirow{3}{*}{ Body mass index (BMI) ${ }^{*}$} & Normal & $203(82.2 \%)$ & $12(50.0)$ & \multirow{3}{*}{$\mathrm{x}^{2}=52.82 ; \mathrm{df}=2 ; \mathrm{p}<0.0001$} \\
\hline & Overweight & $39(15.8)$ & $7(29.2)$ & \\
\hline & Obese & $5(2.0)$ & $5(20.8)$ & \\
\hline \multirow[t]{2}{*}{ Diabetes mellitus } & Present & $84(34.0)$ & $14(58.3)$ & \multirow[t]{2}{*}{$\mathrm{x}^{2}=0.009 ; \mathrm{df}=1 ; \mathrm{p}=0.008$} \\
\hline & Absent & $163(66.0)$ & $10(41.7)$ & \\
\hline \multirow[t]{2}{*}{ Smoking } & Yes & 34 (13.8) & $9(37.5)$ & \multirow[t]{2}{*}{$\mathrm{x}^{2}=12.62 ; \mathrm{df}=1 ; \mathrm{p}<0.0001$} \\
\hline & No & $213(86.2)$ & $15(62.5)$ & \\
\hline \multirow[t]{3}{*}{ Urine culture $^{n * w}$} & UTI & $47(19.0)$ & $7(29.2)$ & \multirow{3}{*}{$\mathrm{x}^{2}=2.141 ; \mathrm{df}=2 ; \mathrm{p}=0.343$} \\
\hline & Sterile pyuria ${ }^{\#}$ & $91(36.9)$ & $8(33.3)$ & \\
\hline & No growth ${ }^{\mathbf{s}}$ & $109(44.1)$ & $9(37.5)$ & \\
\hline \multirow{3}{*}{ Pre-op catheterization } & Urethral & $148(59.9)$ & $15(62.5)$ & \multirow{3}{*}{$\mathrm{FET}=31.754 ; \mathrm{p}<0.0001$} \\
\hline & Suprapubic & $6(2.4)$ & $6(25.0)$ & \\
\hline & None & $93(37.7)$ & $3(12.5)$ & \\
\hline \multirow[t]{2}{*}{ Approach } & Transvesical & $102(41.3)$ & $10(41.7)$ & \multirow{2}{*}{$\mathrm{x}^{2}=0.002 ; \mathrm{df}=1 ; \mathrm{p}=0.969$} \\
\hline & Retropubic & $145(58.7)$ & $14(58.3)$ & \\
\hline \multirow[t]{2}{*}{ Skin incision } & Lower midline & $146(59.1)$ & $14(58.3)$ & \multirow[t]{2}{*}{$\mathrm{x}^{2}=0.002 ; \mathrm{df}=1 ; \mathrm{p}=0.969$} \\
\hline & Pfannenstiel & $101(40.9 \%)$ & $10(41.7)$ & \\
\hline \multirow{3}{*}{ Estimated blood loss } & $<500 \mathrm{mls}$ & $139(56.3)$ & $4(16.7)$ & \multirow{3}{*}{$\mathrm{FET}=33.93 ; \mathrm{p}<0.0001$} \\
\hline & $500-999 \mathrm{mls}$ & $79(32.0)$ & $7(29.1)$ & \\
\hline & $1000-2000 \mathrm{mls}$ & $29(11.7)$ & $13(54.2)$ & \\
\hline \multirow[t]{2}{*}{ Level of surgeon } & Consultant & $126(51.0)$ & $10(41.7)$ & \multirow{2}{*}{$\mathrm{x}^{2}=0.929 ; \mathrm{df}=1 ; \mathrm{p}=0.335$} \\
\hline & Senior registrar & $121(49.0)$ & $14(58.3)$ & \\
\hline \multirow{2}{*}{$\begin{array}{l}\text { Use of suprapubic catheter } \\
\text { for irrigation post- } \\
\text { operatively }\end{array}$} & Yes & $24(9.7)$ & $8(33.3)$ & \multirow[t]{2}{*}{$\mathrm{x}^{2}=16.90 ; \mathrm{df}=1 ; \mathrm{p}<0.0001$} \\
\hline & No & $223(90.3)$ & $16(66.7)$ & \\
\hline $\begin{array}{l}\text { Type of urethral catheter } \\
\text { used post-operatively }\end{array}$ & $\begin{array}{l}\text { Rubber catheter } \\
\text { Silicone coated }\end{array}$ & $\begin{array}{l}179(72.5) \\
68(27.5)\end{array}$ & $\begin{array}{l}21(87.5) \\
3(12.5)\end{array}$ & $\mathrm{FET}=3.010 ; \mathrm{p}=0.096$ \\
\hline \multirow[t]{2}{*}{ Mode of bladder irrigation } & Exogenous (normal & $211(85.4)$ & $22(91.7)$ & \multirow[t]{2}{*}{$\mathrm{FET}=0.832 ; \mathrm{p}=0.545$} \\
\hline & $\begin{array}{c}\text { saline) } \\
\text { Endogenous (diuresis) }\end{array}$ & $36(14.6)$ & $2(8.3)$ & \\
\hline \multicolumn{2}{|l|}{ TOTAL } & $247(100.0)$ & $24(100.0)$ & \\
\hline
\end{tabular}




\section{Discussion}

The rate of SSI found in this study was $9.8 \%$ which is within the range of $1.2-35.0 \%$ that have been previously quoted in literature from different parts of the world ${ }^{7,8,9}$. The risk factors for post-prostatectomy SSI from this audit were emergency operation, obesity, diabetes mellitus (DM), smoking, pre-operative urethral/suprapubic catheterization, excessive haemorrhage and post-operative suprapubic bladder drainage. Age was not found to be a significant risk factor for SSI in our study $(p=0.942)$, similar to findings from other studies ${ }^{10,11}$. Age is however a controversial factor when considering risk factors for SSI. This is because investigators in the past have reported contradictory results concerning the relationship between increasing age and risk of $\mathrm{SSI}^{12}$. Some researchers affirm that increasing age is associated with a greater risk of $\mathrm{SSI}^{13}$ while others believe factors indirectly related to age such as an increased prevalence of co-morbid conditions, increased severity of acute illness and decreased host response to bacterial invasion are the real reasons why older patients appear to have an increased risk of $\mathrm{SSI}^{14}$. A cohort by Kaye et $\mathrm{al}^{12}$ involving 144,485 consecutive surgical patients and 72,139 procedures however concluded that increasing age independently predicted an increased risk of SSI only until age 65 years; while after 65 years, increasing age independently predicted a decreased risk of SSI.

The timing of surgery was a significant risk factor for the development of SSI from this study $(p=0.001)$ and all our patients who had their prostatectomy done as an emergency procedure developed SSI in the post-operative period. Though the reason for this is not clear, it may however not be unconnected with inability to fully optimize the patients before the procedure; which is usually not the case with an elective operation. There were however only few emergency cases in this series $(1.2 \%)$ because our practice is to consider emergency prostatectomy only as a last resort in patients with life threatening haematuria unresponsive to conservative management who have been evaluated to exclude other possible causes of haematuria. Other researchers that have documented their experience with emergency prostatectomy however believe that in well selected patients, there is little or no additional risks from emergency prostatectomy when compared with the elective operation ${ }^{15}$.
More than half $(58.3 \%)$ of the patients with SSI were diabetic, suggesting a significant role for DM as a contributory risk factor for SSI $(p=0.008)$. A possible mechanism for this is DM- associated immunosuppression leading to increased risk of $\mathrm{SSI}^{14}$. Though it is purely coincidental that the ratio of DM to non-DM patients in our series was $1: 2$, there is however a relatively high prevalence of type $2 \mathrm{DM}$ in Nigeria, and a recent meta-analysis reported that the incidence of DM within the country was significantly higher than that of neighboring West African countries ${ }^{16}$.

Previous history of smoking was another significant risk factor for SSI in our study $(\mathrm{p}<0.0001)$. Although a positive smoking history was uncommon in our patients, close to $2 / 3^{\text {rd }}$ of those who smoked developed SSI. It is believed that smoking significantly increases the risk of developing SSI because the nicotine causes local tissue vasoconstriction, reduces oxygen carrying capacity of blood, limits the inflammatory response necessary for elimination of potentially infectious agents and has other adverse effects on wound healing ${ }^{17}$.

Other statistically significant predisposing factors for post-prostatectomy SSI encountered in our audit such as obesity $(p<0.0001)$, excessive blood loss $(p<0.0001)$, as well as pre-operative use of catheters are similar to what have been previously documented in literature by other researchers ${ }^{11,14,18}$. Van Roermund et al18 in their study to evaluate the impact of obesity on outcome of open prostatectomy found higher rates of SSI in obese men, similar to the trend recorded in our study. A possible explanation for this is that adipose tissue is poorly vascularized and the subsequent effect of poor tissue oxygenation and reduced immune function is thought to increase the risk of $\mathrm{SSI}^{17}$. We also found that the higher the blood loss from the operation, the higher the risk of SSI. This seems to corroborate with the findings by Zargooshi ${ }^{8}$ who reviewed 3,000 open prostatectomy procedures and reported that SSI was more prevalent in those patients whose operations were complicated by excessive bleeding, since these patients often needed blood transfusion and sometimes, re-operation.

Another risk factor for SSI encountered in our patients was the use of catheters in the pre-operative period. This is not surprising; as bacterial colonization is an inevitable 
sequel of catheterization ${ }^{19}$ and this is a potential source for organisms to gain access to the wound and cause SSI. This may be especially true in patients with suprapubic cystostomy (SPC) since all our patients on SPC at the time of (secondary) prostatectomy developed SSI. The use of a suprapubic catheter to aid bladder irrigation post-operatively equally increased the risk of SSI ( $p<0.0001)$, possibly due to similar increased risk of bacterial inoculation into the wound, aided by proximity of the suprapubic catheter to the wound site. It is however quite difficult to wean patients off use of catheter in the pre-operative period in our environment since many of them present late with severe lower urinary tract symptoms and complications such as urinary retention. An important issue that needs to be pointed out is however that we had more patients with sterile pyuria (91 patients; 36.9\%) than those with confirmed UTI (47 patients; 19\%) in our series. This may not be unconnected with the fact that some of the common antibiotics may sometimes be purchased without a prescription and abuse of such antibiotic medications possibly reduced the chances of isolating the culprit organism from the urine of patients with sterile pyuria.

The level of training and skills of the surgeon were not significant determining factors for SSI from our study $(p=0.335)$. This is not in line with previous documentation from literature, but our finding may be partly explained by fact that the residents involved in performing the surgeries were already in the final stages of their residency training and were quite familiar with the procedure since it is done on a routine basis in our unit. The studies that documented lower infection rates in surgeries performed by consultants attributed this to better surgeon experience, shorter surgery duration and less bleeding from the procedure, as these factors may contribute to the development of SSI, either singly or in combination ${ }^{20}$. The surgical approach (transvesical vs retropubic), location of incision (lower midline vs pfannenstiel), catheter type (rubber vs silicone) and modality of irrigation (exogenous vs endogenous) were not statistically significant contributors to occurrence of SSI from this study.

As with any scientific research, there a number of confounding issues for this study. First is that all the patients were managed post-operatively on a general ward shared with other surgical sub-specialty units and this may have contributed adversely to the wound outcomes. Our second limitation was that being a retrospective study, we couldn't exhaust all the possible risk factors for SSI and some of these such as the timing of admission and duration of surgery were not considered in our study.

\section{Conclusion}

SSI is a recognized complication of open simple prostatectomy. Identified risk factors for its occurrence from this audit are emergency operation, obesity, DM, smoking, pre-operative urethral/suprapubic catheterization, excessive haemorrhage and post-operative suprapubic bladder drainage. Age, approach to prostatectomy (retropubic vs transvesical), incision type (lower midline vs pfannenstiel), level of the surgeon, catheter type and modality of irrigation were however not significant risk factors for post-prostatectomy SSI in this study.

\section{Funding/material support}

None.

\section{Conflict of interet}

None declared.

\section{References}

1. Owens CD, Stoessel K. Surgical site infections: epidemiology, microbiology and prevention. The Journal of Hospital Infection. 2008; 70 (Suppl 2): 3-10.

2. Adisa AO, Lawal OO, Adejuyigbe O. Evaluation of two methods of preoperative hair removal and their relationship to postoperative wound infection. Journal of Infection in Developing Countries. 2011; 5 (10): 717-722.

3. Badia JM, Casey AL, Petrosillo N, Hudson PM, Mitchell SA, Crosby C. Impact of surgical site infection on healthcare costs and patient outcomes: a systematic review in six European countries. The Journal of Hospital Infection. 2017; 96 (1): 1-15.

4. Alhasan SU, Aji SA, Mohammed AZ, Malami S. Transurethral resection of the prostate in Northern Nigeria, problems and prospects. BMC Urology. 2008; 8:18.

5. Salako AA, Badmus TA, Owojuyigbe AM, David RA, Ndegbu CU, Onyeze CI. Open Prostatectomy in the Management of Benign Prostate Hyperplasia in a Developing Economy. Open Journal of Urology. 2016; 6 (12): 179-190.

6. Tubaro A, de Nunzio C. The current role of open surgery in BPH. European Urology. 2006; 4 (5): 191-201.

7. Shamim M, Idrees M, Bano S. Outcome of Open Prostatectomy. Journal of Surgery Pakistan. (International) 2012; 17 (3): 87-92

8. Zargooshi J. Open prostatectomy for benign prostate hyperplasia: short-term outcome in 3000 consecutive pa- 
tients. Prostate Cancer and Prostatic Diseases. 2007; 10 (4): 374-377.

9. Oranusi C, Nwofor A, Oranusi I. Complication rates of open transvesical prostatectomy according to the Clavien-Dindo classification system. Nigerian Journal of Clinical Practice. 2012; 15 (1). 34-37

10. Marmiroli R, Antunes AA, Reis ST, Nakano E, Srougi M. Standard surgical treatment for benign prostatic hyperplasia is safe for patients over 75 years: analysis of 100 cases from a high-volume urologic center. Clinics. 2012; 67 (12): 1415-1418.

11. Cheng K, Li J, Kong Q, Wang C, Ye N, Xia G. Risk factors for surgical site infection in a teaching hospital: a prospective study of 1,138 patients. Patient Preference and Adherence. 2015; 9: 1171-1177.

12. Kaye KS, Schmit K, Pieper C, Sloane R, Caughlan KF, Sexton DJ et al. The effect of increasing age on the risk of surgical site infection. Journal of Infectious Diseases. 2005; 191 (7): 1056-1062.

13. Abreu D, Campos E, Seija V, Arroyo C, Suarez R, Rotemberg P et al. Surgical site infection in surgery for benign prostatic hyperplasia: comparison of two skin antiseptics and risk factors. Surgical Infections. 2014; 15 (6): 763-767.

14. Raymond DP, Pelletier SJ, Crabtree TD, Schulman AM, Pruett TL, Sawyer RG. Surgical infection and the aging population. The American Surgeon. 2001; 67 (9): $827-$ 832.

15. Orakwe J, Okafor P. Emergency transvesical prostatectomy: A review of fifty cases. Tropical Journal of Medical Research. 2012; 16 (2): 46-49.

16. Adeloye DO, Ige JO, Aderemi AV, Adeleye N, Amoo EO, Auta A et al. Estimating the prevalence, hospitalisation and mortality from type 2 diabetes mellitus in $\mathrm{Ni}$ geria: a systematic review and meta-analysis. BMJ Open. 2017; 7 (5): e015424.

17. National Collaborating Centre for Women's and Children's Health (UK). Surgical Site Infection: Prevention and Treatment of Surgical Site Infection. NICE Clinical Guidelines No 74. London: RCOG Press, 2008.

18. van Roermund JG, van Basten J, Kiemeney LA, Karthaus HF, Witjes JA. Impact of obesity on surgical outcomes following open radical prostatectomy. Urologia Internationalis 2009: 82 (3): 256-261.

19. Feneley RC, Hopley IB, Wells PN. Urinary catheters: history, current status, adverse events and research agenda. Journal of Medical Engineering \& Technology 2015: 39 (8): 459-470.

20. Adam C, Hofstetter A, Deubner J, Zaak D, Weitkunat $\mathrm{R}$, Seitz $\mathrm{M}$ et al. Retropubic transvesical prostatectomy for significant prostatic enlargement must remain a standard part of urology training. Scandinavian Journal of Urology and Nephrology 2004; 38 (6): 472-478. 